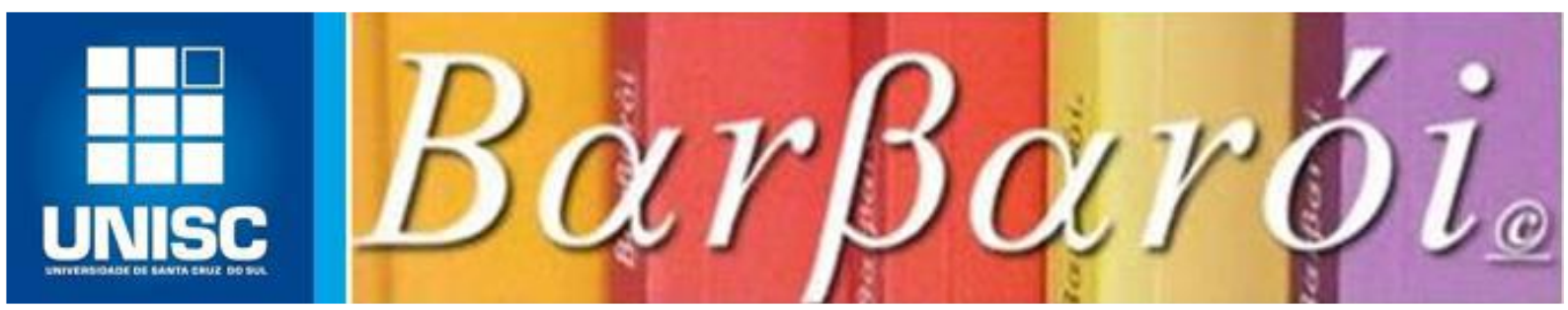

\title{
TEMPOS DE COLAPSO, TEMPOS DE LUTAS: CONTRIBUIÇÕES DO TRABALHO EDUCATIVO NO SERVIÇO SOCIAL
}

\author{
DOI: http://dx.doi.org/10.17058/barbaroi.v0i0.14688 \\ $*$
}

\author{
Lindamar Alves Faermann \\ Universidade de Taubaté - UNITAU - Brasil
}

Angela Michele Suave

Universidade de Taubaté - UNITAU - Brasil

$*$

\section{Resumo}

Este artigo reflete sobre as possibilidades do trabalho educativo no campo profissional do Serviço Social e suas implicações ideopolíticas no cotidiano de vida dos sujeitos atendidos pelos assistentes sociais em seus diferentes espaços de atuação. A conjuntura brasileira, marcada por enormes desafios decorrentes da ofensiva neoliberal em pleno vapor, do avanço da extrema direita e do irracionalismo que tomou conta do país, sobretudo nos últimos dois anos (pré e pós-eleição Bolsonaro), tem exigido dos profissionais intervenções que recuperem e/ou privilegiem o trabalho educativo junto à população usuária, valendo-se de mediações político-pedagógicas que contribuam com a formação de sua consciência crítica, tendo em vista a construção de ideias e de práticas contra-hegemônicas, bem como o reconhecimento dos processos de espoliação que vivenciam para que busquem o atendimento de suas necessidades. Nessa direção, aponta-se a contribuição do pensamento de Gramsci e de Paulo Freire para viabilizar o trabalho educativo no Serviço Social sob as bases do projeto éticopolítico profissional, de modo que seja possível ampliar percepções, sentidos e ações, além de ousar e resistir frente ao colapso instalado na sociedade brasileira.

Palavras-chave: Serviço Social, Trabalho Educativo, Contribuições de Grasmci e Paulo Freire.

\section{Introdução}

Em tempos de devastação dos direitos sociais e de ascensão da ideologia e de forças políticas da extrema direita, portanto de uma conjuntura em que obscurantismo tomou conta de setores expressivos da sociedade brasileira, cabe ao Serviço Social convergir suas forças e ações para fortaleceras lutas em curso no país, bem como valer-se de todas as mediações político-pedagógicas para estimular a consciência crítica da população usuária acerca das injustiças e dos sofrimentos que atravessam sua vida. 
Trata-se de um momento de ataque absoluto às políticas públicas e aos direitos sociais que, além de duramente conquistados no Brasil, foram tardiamente reconhecidos pelo poder público. Esse momento, caracterizado nos termos de Behring (2003) de contrarreforma ${ }^{1}$ do Estado, vem atingindo frontalmente a política educacional, tanto por meio da aprovação da PEC 241 em 2016, que limitou por 20 anos os gastos nessa área, quanto pela desqualificação e controle do pensamento crítico, mediante políticas de silenciamento como Escola Sem Partido $^{2}$ e a constante perseguição e assédio docente. Afora, o desrespeito aos professores e alunos, os cortes de verbas das Universidades públicas, e os reiterados insultos ao nome e ao legado de Paulo Freire, tornando-se imprescindível, diante desse momento fazer da opressão objeto de reflexão e luta dos oprimidos.

Paulo Freire, ao trazer a ideia de que a emancipação dos sujeitos passa necessariamente pela conscientização das relações que se estruturam entre oprimidos e opressores, oferece caminhos substantivos, mediados pela educação, para o desenvolvimento de práticas sociais que fomentem o pensar crítico da população - algo tão temerário e fortemente rebatido por governantes que ocupam hoje o Congresso brasileiro.

A educação popular defendida por Freire é uma educação alicerçada na práxis. O que implica, além de uma abordagem crítica do mundo, a ação consciente sobre ele. Para o autor, sem esse processo não há como entender e superar as contradições do sistema capitalista, pois sua transformação passa pela reflexão e ação dos homens. Por isso, afirma que não se "pode basear na crença de que é dentro da consciência que se opera a transformação do mundo, a criação do mundo. É dentro do próprio mundo que, na história, através da práxis se dá o processo de transformação". (FREIRE, 1979, p.115). Neste sentido, a gênese do pensamento freireano é uma bússola para intervenções profissionais que almejem o pensar e o fazer libertário e questionador da população, pois segundo ele:

\footnotetext{
Quem melhor que o oprimido, se encontrará preparado para entender o significado terrível de uma sociedade opressora? Quem sentirá, melhor que eles, os efeitos da opressão? Quem mais que eles, para ir compreendendo a necessidade da libertação? Libertação a que não chegarão pelo acaso, mas pela práxis de sua busca; pelo conhecimento e reconhecimento de lutar por ela. (FREIRE, 1977, p. 42).
}

Assim, ao pretendemos contribuir com as lutas, reivindicações e com o atendimento das necessidades da classe trabalhadora, mediadas pela ação profissional e pela organização

\footnotetext{
${ }^{1}$ Termo utilizado pela autora para abordar a particularidade da "reforma social" brasileira, expressa num contexto de reconhecimento tardio dos direitos sociais no Brasil e do seu desmonte em curtíssimo tempo.

${ }^{2}$ Embora o PL Escola Sem Partido tenha sido arquivado recentemente (11 de julho de 2019) pelo presidente da Comissão, Marcos Rogério do DEM, alguns parlamentares já anunciaram que pretendem retomá-lo no ano de 2020.
} 
política da categoria, temos que fortalecer uma pedagogia ancorada em princípios socialistas que tomem a educação popular como ferramenta cotidiana de trabalho.

O Serviço Social insere-se na divisão sociotécnica do trabalho como uma atividade especializada sob a forma de serviços interferindo na realidade material e subjetiva dos sujeitos. Nesse sentido, por meio de sua ação, participa do processo de reprodução das relações sociais através da oferta de recursos, bens e serviços, e igualmente por meio da ressignificação de ideias, de sentidos e de novas práticas.

A forma como as ações profissionais são operacionalizadas e/ou mobilizadas, está diretamente atrelada à perspectiva teórica do profissional processando-se conforme os distintos projetos de profissão e de sociedade. Nesse sentido, orientam-se para um campo em disputa, "tanto do processo de reprodução dos interesses de preservação do capital, quanto das respostas às necessidades de sobrevivência dos que vivem do trabalho". (YAZBEK, 1999, p. $90)$.

$\mathrm{Na}$ direção do projeto ético-político, o trabalho educativo compreende a formação da consciência crítica dos usuários frente à realidade que vivenciam, com vistas à sua organização, mobilização e emancipação política. Ressalta-se que, em Marx (2010), a emancipação política é apontada como uma etapa da emancipação humana. Segundo o autor, a emancipação humana consiste na liberdade plena do indivíduo, e não apenas na liberdade política adquirida no Estado burguês; portanto, tal condição só pode efetivar-se com a ruptura da propriedade privada e com a constituição de uma nova sociabilidade. Portanto,

[...] a emancipação humana só estará plenamente realizada quando o homem individual real tiver recuperado para si o cidadão abstrato e se tornado ente genérico na qualidade de homem individual, nas suas relações individuais, quando o homem tiver reconhecido e organizado suas forças próprias como forças sociais e, em consequência, não mais separar de si mesmo a força social na forma de força política. (MARX, 2010, p. 53).

Embora a construção de uma nova ordem social esteja no centro do projeto éticopolítico do Serviço Social brasileiro, no contexto da sociedade capitalista o trabalho do assistente social efetua-se no campo da emancipação política, logo das conquistas e lutas relativas aos direitos sociais, civis e políticos.

Ressalta-se que, em linhas gerais, o termo educativo designa a natureza das ações desenvolvidas junto aos sujeitos nos mais diversos espaços sócio-ocupacionais em que os assistentes sociais se inserem, sendo tomado como qualificador do trabalho, indicando um campo de aprendizagem voltado ao "desenvolvimento de capacidades substantivas e valores 
éticos, estéticos e políticos a fim de promover o acesso e o processamento de informações, a convivência em grupo e a participação na vida pública”. (COSTA, 2004, p. 48).

A proposta de um trabalho de cunho educativo no Serviço Social tem raízes nas protoformas da profissão. Nesse contexto, as ações dos assistentes sociais respondiam, predominantemente, ao controle exercido pela burguesia para a cooperação dos trabalhadores com o processo de reprodução social consubstanciado na exploração capitalista e na dominação ideológica. Sob esse aspecto, os assistentes sociais direcionavam sua intervenção às demandas institucionais, objetivando a conciliação entre capital e trabalho.

Assim, entre as ações que marcaram o surgimento do Serviço Social no Brasil, assinalam-se as de caráter educativo com viés conservador, cujos objetivos eram a vigilância, a adaptação e o ajustamento dos indivíduos na sociedade capitalista. De acordo com Iamamoto (1993, p. 115), por meio dessas ações, almejava-se obter "mudanças na maneira de ser, de sentir, de ver e agir dos indivíduos" - em suma, a sua adesão às propostas profissionais e às políticas institucionais. E isso incidia "tanto sobre questões imediatas, como sobre a visão global de mundo dos clientes".

Nessa direção, a intervenção do assistente social orientava-se pela perspectiva positivista. $\mathrm{O}$ homem era visto como produto das relações intrínsecas entre sua personalidade e o meio social, cabendo ao profissional trabalhar as características e as qualidades pessoais dos operários e de suas famílias, para sua integração na sociedade burguesa.

\footnotetext{
Coerente com essas expectativas, o assistente social passa a assumir uma série de funções relacionadas com a agilização e maximização dos recursos institucionais, bem como com a ação educativa e normativa do ajustamento psicossocial de parcelas crescentes do proletariado urbano, principalmente mulheres e crianças. (RAICHELIS, 1988, p. 74).
}

Buscava-se, assim, um trabalho reformulador do caráter, centrado no indivíduo e que privilegiasse a dimensão restauradora da moral e dos bons costumes, abalados no nível das relações sociais. Tais relações eram analisadas no plano subjetivo e imediato, e as respostas aos problemas apresentados centravam-se essencialmente nas questões da personalidade do indivíduo e de sua adaptação às normas sociais.

A incorporação pelo Serviço Social das ideias positivistas reforçou, no âmbito profissional, o desenvolvimento de ações com viés instrumental, ou seja, ações centradas em procedimentos técnicos focados na superficialidade dos processos sociais, e não nas suas determinações fundantes. Essas ações objetivavam alterações no contexto empírico e resoluções pontuais das situações tidas como problemáticas individuais, morais ou 
patológicas, imperando "uma relação direta entre pensamento e ação e onde os meios (valores) se subsumiam aos fins". (GUERRA, 2010, p. 10).

Os questionamentos a essa perspectiva iniciam-se no âmbito da renovação profissional, sobretudo, após a consolidação da vertente de intenção de ruptura, que, ancorada na tradição marxista, apontou elementos que contribuíram para uma análise crítica da profissão. Dessa forma, foi justamente a partir de suas reflexões,

[...] que se pôde colocar o rol de inquietudes relativas ao processo histórico do Serviço Social, sua relação com as estratégias de classe e o poder condensado no Estado, sua articulação com as várias construções ideológicas e seu processamento como prática profissional no âmbito de instituições sociais determinadas. A requisição que dela derivou - a do assistente social como um tipo particular de intelectual - colaborou decisivamente para girar a face do profissional, propondo-o, ademais de um agente técnico especializado, como um protagonista voltado para o conhecimento dos seus papéis sociopolítico e profissional, envolvendo exigências teóricas mais rigorosas. (NETTO, 2001, p. 302).

Foi nos marcos desse processo que se colocou a necessidade de se construir um projeto profissional, arquitetado aos interesses e as demandas da classe trabalhadora. Portanto, o Serviço Social ao adotar o marxismo como referência analítica e interventiva ampliou suas competências teóricas, políticas e operativas, desenvolvendo-se no campo investigativo acerca da natureza de sua formação e de sua história e, especialmente, acerca da realidade econômica, política, social e cultural, diante da qual se inscreve como profissão na divisão social e técnica do trabalho.

Nesse sentido, no momento em que a profissão se redefiniu, no campo marxista, as ações profissionais instituíram-se sob outras finalidades, objetivando práticas educativas direcionadas à construção de uma nova cultura, alicerçada nas lutas, necessidades e saberes populares, capaz de instigar questionamentos e intervenções na ordem social, ou nos termos de Grasmci (2004), de realizar a contra-hegemonia.

Vale lembrar que em Grasmci (2004), a hegemonia é a forma pela qual se afirma a direção e o poder de um bloco social e, ao mesmo tempo, o terreno para superar a subalternidade e atingir uma nova consciência de classe. $\mathrm{O}$ autor usa esse conceito para explicar os dispositivos de exercício da hegemonia das classes dominantes e, concomitantemente, estabelecer uma base teórica que subsidie formas contra estratégicas proletárias de enfrentamento das adversidades do capitalismo. Desse modo, a hegemonia apresenta-se como um recurso contrário à expectativa passiva das consequências decorrentes do modus operandi do capitalismo.

Gramsci foi um dos principais estudiosos do século XIX a se deter sobre o conceito de hegemonia, apresentando reflexões importantes acerca do tema para pensar as relações 
sociais, sem pender para o idealismo e o materialismo vulgares, evidenciando um conceito amplo de transformação social, calcado na relação entre estrutura e superestrutura, na qual as dimensões econômicas, políticas e ideológicas são vetores centrais desse processo, deixando claro que as mudanças estruturais não estão desvinculadas das mudanças culturais. Isso porque, para ele, a "estrutura e as superestruturas formam um 'bloco histórico', isto é, o conjunto complexo e contraditório das superestruturas é o reflexo do conjunto das relações sociais de produção". (GRAMSCI, 2004, p. 250).

Para o pensador, não há como transformar a realidade sem considerar o papel que as ideologias exercem na vida social, pois a construção de uma nova hegemonia - base para se projetar um novo modelo de sociedade - requer uma crítica radical às ideias dominantes. A realização dessa crítica é, segundo o autor, tarefa da filosofia da práxis; uma filosofia que supera o senso comum e que leva os homens a adquirem consciência social sobre suas mazelas.

A ideologia, no pensamento gramsciano, é algo que se objetiva na realidade, influenciando diretamente a vida social. E é no circuito do senso comum (modo de pensar desorganizado, fragmentado, principiante e folclórico) que os trabalhadores incorporam as ideias dominantes, apresentadas como verdades implacáveis e universais.

Neste sentido, seu conceito de transformação permite o enfoque no âmbito da consciência e da luta ideológica oferecendo alternativas para o desenvolvimento, no Serviço Social, de práticas educativas que possibilitem à população fazer uso social e político dos conhecimentos e das informações adquiridas para ampliar sua visão e buscar formas de enfrentamentos das desigualdades existentes.

Tendo por base essas reflexões, o presente artigo foi construído por meio de pesquisa bibliográfica e documental ${ }^{3}$ com o fito de reunir informações e aprofundar conhecimentos acerca do objeto estudado. Em sua estruturação, considerou-se dois eixos analíticos. O primeiro eixo é constituído por problematizações acerca do trabalho educativo no Serviço Social, evidenciando tendências e alguns vieses dessa discussão no campo profissional. O segundo destaca as finalidades e os pressupostos do trabalho educativo na perspectiva do

\footnotetext{
${ }^{3}$ Conforme esclarece Gil (1999, p. 48), a pesquisa documental vale-se de materiais que ainda não receberam um tratamento analítico ou que, ainda, podem ser reelaborados de acordo com a problemática da pesquisa, ao passo que a pesquisa bibliográfica é desenvolvida a partir de material concluído, composto "principalmente de livros e artigos científicos. Embora em quase todos os estudos seja exigido algum tipo de trabalho dessa natureza, há pesquisas desenvolvidas exclusivamente a partir de fontes bibliográficas".
} 
projeto ético-político, valendo-se do pensamento gramsciano para orientar tais argumentações.

\section{Problematizações sobre o trabalho educativo no Serviço Social}

Neste artigo, não será feita distinção entre os termos função educativa, trabalho socioeducativo e função pedagógica ${ }^{4}$, visto que guardam relações entre si e reportam-se a uma das dimensões constitutivas do trabalho profissional do assistente social. Apesar disso, vale esclarecer que o termo socioeducativo recebe outra conotação ao ser utilizado, no âmbito da legislação brasileira, para caracterizar as medidas previstas no Estatuto da Criança e do Adolescente (ECA).

Nesse campo, a Doutrina de Proteção Integral, sancionada pelo ECA, assinala que o caráter socioeducativo deve ser o eixo principal das medidas ${ }^{5}$ aplicadas em resposta ao ato infracional. Portanto, quando referenciada ao marco legal, o socioeducativo remete a uma educação voltada para o convívio social, que permita ao adolescente retornar a esse contexto sem que volte a quebrar as normas de convivência e aprenda a se relacionar consigo mesmo e com os outros (COSTA, 2004).

Outra questão a se pontuar sobre o trabalho educativo diz respeito à banalização, à redução e à simplificação do que constitui essa atividade no Serviço Social. Ao se conversar com alunos e profissionais, é habitual que exponham que, em seus espaços de estágio e de trabalho, desenvolvam práticas dessa natureza. Esse discurso parece ter-se tornado hegemônico no meio profissional, sem a devida problematização e crítica. No entanto, ao explicitarem o que são e como são realizadas, percebe-se que não há clareza, reportando-se, de modo geral, ao desenvolvimento de reuniões organizadas em forma de palestras ou de encontros mensais. Ou então, o que é mais agravante, associam inadequadamente as ações educativas às atividades marcadamente despolitizadas, com características tipicamente "festivas". (FAERMANN, 2014)

\footnotetext{
${ }^{4}$ Segundo Ghiraldelli (1987, p.89), a pedagogia consubstancia-se no pólo teórico da problemática educacional, vinculando-se "aos problemas metodológicos relativos ao como ensinar, ao que ensinar e, também ao quando ensinar e para quem ensinar (...). Eu poderia afirmar, grosso modo, que a pedagogia é a teoria, enquanto a educação é a prática". Logo, a educação, enquanto práxis é objeto da pedagogia e se refere ao processo de formação ética dos sujeitos, à transferência e à aquisição de valores e à apreensão da história, da memória e da cultura.

${ }^{5}$ São elas: advertência; obrigação de reparar o dano; prestação de serviços à comunidade; liberdade assistida; inserção em regime de semiliberdade; internação em estabelecimento educacional. Essas medidas socioeducativas podem ser complementadas com medidas protetivas previstas no art. 101 do Estatuto da Criança e do Adolescente.
} 
A esse respeito, Vasconcelos (2012) evidencia que, no âmbito da política de assistência social, é habitual assistentes sociais e psicólogos realizarem esse tipo de atividade, com o objetivo de trabalhar a autoestima da população por meio de encontros em que são utilizadas dinâmicas específicas de integração e reflexão. Conforme a autora, são propostas que, no limite, auxiliam no alívio temporário de suas tensões e estimulam a ajuda mútua, como é o caso da terapia comunitária ${ }^{6}$.

Assim, a narrativa de muitos profissionais e alunos acerca do trabalho educativo é semelhante, pois de modo geral, dizem trabalhar a cidadania, a democracia e a emancipação dos usuários no âmbito dessa ação. Diante dessa realidade, é comum constatar certo "pensamento mágico de que basta postular os pressupostos da autonomia, da emancipação e da participação para que as ações socioeducativas na perspectiva do projeto ético-político se autorrealizem". (MIOTO; LIMA, 2009, p. 31).

Frente a tais situações, o trabalho educativo tem-se transformado numa atividade banal, desvinculada de aportes teóricos e políticos e da necessária qualificação para sua realização. É preciso lembrar que não estamos falando de um trabalho desprovido de sentido, mas de uma ação teleológica, direcionada para um fim, dado que "trabalhar é agir sobre a natureza, agir sobre a realidade, transformando-a em função dos objetivos, das necessidades humanas". (SAVIANI, 1986, p. 14).

Na perspectiva marxista, o homem é um ser que se autocria. Por meio do trabalho, ele satisfaz suas necessidades (imediatas ou não), estabelece relações com os outros homens, bem como cria produtos e condições para sua própria existência. Assim, mediante o trabalho, o homem transforma a natureza, transformando a si mesmo. Trata-se, portanto, de uma relação de transformação mútua.

Esse processo de transformação da natureza pela ação do homem (trabalho) é sempre acompanhado de intencionalidades, embora nem sempre conscientes. Logo, antes mesmo de concretizar suas atividades, o homem realiza uma prévia ideação: uma antecipação ideal das finalidades que pretende alcançar. A antecipação do produto de sua ação faz parte do que Marx (2001) chama de processo de trabalho - que ao ser objetivado, resulta em práxis.

O mesmo ocorre com o trabalho do assistente social, uma vez que suas ações são sempre mediadas por finalidades e têm implicações diretas na vida dos usuários. Consequentemente por meio dos serviços prestados, o profissional interfere não apenas na

\footnotetext{
${ }^{6}$ A Terapia Comunitária refere-se a uma metodologia de intervenção em comunidades. Foi desenvolvida a partir de 1988, em Fortaleza (CE), pelo Prof. Dr. Adalberto de Paula Barreto, médico psiquiatra, antropólogo e docente do Curso de Medicina Social da Universidade Federal do Ceará. Surgiu a partir de sua experiência profissional com pessoas encaminhadas por um Centro de Direitos Humanos, que apresentavam sofrimentos psíquicos.
} 
reprodução social dos indivíduos como também na sua consciência, ou seja, na reprodução ídeo-política. Como recorda Iamamoto (2002, p.69), o assistente social não atua apenas no campo material; sua intervenção tem "também efeitos na sociedade como um profissional que incide no campo do conhecimento, dos valores, dos comportamentos, da cultura, que, por sua vez, tem efeitos reais na vida dos sujeitos".

Dissociar a prestação de um serviço material dos conteúdos ideológicos que ele veicula é operar burocraticamente, concebendo a possibilidade (impossível) de uma intervenção profissional neutra em que o assistente social se transforma, de modo passivo e indiferente, em um mero veículo de passagem de algo exterior a ele.

Outro entrave no campo profissional acerca do trabalho educativo relaciona-se à ideia de que é preciso implementar certos projetos ou programas para materializar esse tipo de trabalho. A vigência dessa ideia expressa, por um lado, lacunas na formação e, por outro, é corroborada por tal associação nos documentos e marcos políticos e legais existentes, como apresentado pela política de assistência social, em que o trabalho educativo aparece ligado a ações com grupos e alguns serviços específicos.

No entanto, por ser a dimensão educativa um componente ontológico do trabalho do assistente social, o profissional a mobiliza durante todo o seu processo interventivo: nas entrevistas, nos atendimentos, nos acolhimentos, nas visitas domiciliares, nas reuniões, nos processos grupais, enfim. Assim, ainda que o profissional esteja realizando um atendimento para repasse de recurso, dialeticamente articulada a essa atividade material, desenvolve práticas educativas. Nesse sentido, não é preciso existir um projeto e/ou programa específico para movimentá-las. Mesmo que o profissional não tenha clareza desse processo, todo ato profissional é um ato educativo e político por natureza. Conforme esclarece Prates (2003):

A simples distribuição do recurso não caracteriza uma intervenção profissional; no
entanto, existem situações em que é necessária a utilização de um recurso desta
ordem, o que não dispensa o profissional de estabelecer vínculos, provocar
reflexões, realizar mediações ou o apoio social. (PRATES, 2003, p.3).

Importa lembrar que o trabalho do assistente social é determinado pelas relações entre as classes na sociedade capitalista, interferindo no processo de reprodução social dos usuários por meio de ações materiais e educativas. As mediações históricas, por meio das quais as ações materiais são desenvolvidas, referem-se àquelas que particularizam o trabalho do assistente social na divisão sociotécnica do trabalho - a viabilização de direitos mediante as políticas sociais e institucionais. Quanto às ações profissionais de natureza educativa, estas são mediatizadas por práticas que influenciam no processo de consciência dos usuários, em que são refletidos e alterados modos de pensar e de agir perante sua vida cotidiana. 
Vale ainda esclarecer que, embora a dimensão educativa seja um componente ontológico do trabalho profissional, a forma como se explicita na intervenção do assistente social está diretamente vinculada à sua perspectiva teórico-metodológica, ao seu compromisso ético-político e à sua capacidade técnico-operativa -noutros termos, à sua visão de homem e de mundo e ao acervo de conhecimentos e de saberes de que dispõe. Nesse sentido, o trabalho educativo requer:

[...] diferentes competências e atribuições configurando modalidades interventivas que partem da identificação de necessidades sociais individuais, familiares ou coletivas, com crítica e sistematização das condições de vida da população usuária, resultando em informação, orientação e formação reflexiva, na perspectiva do reconhecimento e atendimento às necessidades básicas, no acesso aos direitos, serviços e equipamentos públicos. Procedimentos metodológicos direcionados pelos princípios ético-políticos possibilitam o desenvolvimento de abordagens que coletivizem as reflexões, transfigurem a cultura da ajuda e resultem em novas práxis. (SILVEIRA, 2009, p. 356).

No entanto, o fato de ser um trabalho educativo não traz garantia de que se realize numa direção crítica, visto que tanto pode assumir feições disciplinadoras, direcionadas ao "enquadramento dos 'clientes' em sua inserção institucional e na vida social, como pode se voltar para uma perspectiva emancipatória, defendendo, preservando e efetivando direitos sociais”. (YAZBEK, 2006, p. 28). Dessa forma,

Precisamos pensar em como mobilizar, como instigar reflexos no sentido de ampliar consciência, como também instigar a organização interna, particular e coletiva. $\mathrm{O}$ debate sobre processos sociais emancipatórios é também fundamental para que não se reitere, mesmo movimentando os instrumentos com habilidade, processos subalternizadores, enquadradores, conformadores (PRATES, 2013, p.03)

Na mesma linha argumentativa, Freire (2013) destaca que a prática educativa orientase para a libertação dos homens (educação crítica) ou ainda para a sua dominação (educação conservadora). Segundo o autor, a educação conservadora guarda relação direta com a educação bancária, conceito cunhado por ele para designar as relações verticalizadas e os processos desiguais, em que há um sujeito ativo, que ensina-deposita, e um sujeito passivo, que aprende-recebe. Em sua perspectiva, essa educação está claramente vinculada ao projeto burguês, alheio ao desvelamento do real e da razão de ser dos fatos.

Trazendo algumas expressões da educação conservadora para o Serviço Social, tem-se como exemplo o estabelecimento de relações autoritárias que instalam, no cotidiano profissional, um processo denominado por Rios (2006, p. 20) de alienação ética, "que é o que ocorre quando olhamos os outros sem vê-los, ou quando vemos sem crítica, quando não reparamos". 
Ao se trabalhar sob essa lógica, desconhece-se o modo como os usuários entendem e ressignificam as informações transmitidas e os saberes partilhados. Daí ser preciso que, em suas intervenções, os assistentes sociais pautem-se no respeito e na recusa de toda e qualquer forma de autoritarismo e arbitrariedade, na medida em que a ética é condição para o exercício profissional e para a vida em sociedade - não é convite nem mera carta de intenções, devendo ser a objetivação concreta dos valores humano-genéricos defendidos pela categoria. Dessa forma, a consideração pelo saber e pela história de cada um deve ser uma das primeiras lições de ética a se materializar na relação entre o assistente social e o usuário.

\section{Contribuições de Gramsci e de Paulo Freire: o trabalho educativo na perspectiva do projeto ético-político profissional}

Dentre os pressupostos que regem o trabalho educativo na perspectiva do projeto ético-político, destaca-se a premência em contemplar as demandas dos usuários e sua participação no âmbito institucional. Não é incomum existir, na Instituição, serviços e projetos desconectados da sua realidade social e que, por isso mesmo, não os interessam, já que não respondem suas aspirações e necessidades concretas.

Se não tornarmos nossos locais de trabalho em espaços de participação efetiva da população, e não permitirmos que os usuários exercitem o protagonismo político nesses espaços, como vão habilitar-se a serem controladores do Estado no campo das políticas sociais? Ao nos comprometemos com uma prática profissional vinculada aos interesses históricos dos trabalhadores, esse é um dos requisitos básicos, ainda que negligenciados em muitos projetos e intervenções profissionais.

Considerando, nesse contexto, os determinantes da realidade de trabalho do assistente social, bem como as exigências de aumento da produtividade e de alcance de resultados imediatos, vê-se que nem sempre os profissionais dispõem de tempo hábil para realizar atendimentos que permitam estimular processos reflexivos. Em resposta a isso, uma das estratégias para garantir seu desenvolvimento é o trabalho com grupos. O trabalho grupal é um recurso valioso para provocar ações educativas, pois permite coletivizar as demandas sociais que, aparentemente, mostram-se individualizadas.

Quando uma pessoa vive uma injustiça solitariamente, tende à revolta, mas em certas circunstâncias pode ver em outras pessoas sua própria contradição. [...]. Uma mulher, por exemplo, submetida a condições de opressão em casa, condenada aos trabalhos domésticos, pode viver isso a vida toda como natural, portanto, para ela inevitável. Mesmo o desmoronar da idealização na família diante das condições reais do cotidiano pode gerar no máximo a revolta, a constatação de uma terrível "sina". No entanto, essa mesma mulher, num grupo em que possa ver em outras 
companheiras a mesma sina, julgada somente sua, só sua, pode começar a desenvolver uma ação contra o que considera injusto. (IASI, 2011, p. 29).

Nesse sentido, o trabalho educativo, na perspectiva do projeto ético-político, deve instaurar a reflexão crítica, levantar dúvidas, evidenciar as contradições da sociedade burguesa e problematizar o que está naturalizado, concebido como verdadeiro, acabado e imutável. Assim, cabe ao profissional que não se sujeita à ordem vigente realizar nos termos de Andaló (2006), o processo de "desamordaçamento" da realidade social, discutindo com a população usuária as desigualdades e opressões vivenciadas cotidianamente, visto que as demandas que chegam às instituições, apresentadas por "indivíduos, grupos ou famílias, são reveladoras de processos de sujeição à exploração, de desigualdades nas suas mais variadas expressões ou de toda sorte de iniquidades sociais". (MIOTO, 2009, p. 503).

Igualmente, o trabalho educativo deve possibilitar a percepção de que a situação vivida pelos usuários não é destino certo ou vontade de Deus. Por conseguinte, deve explicitar que a existência de classes não é algo acidental, sorte ou azar, é construção e possibilidade humana. Por isso, Marx e Engels (1998) apontam o papel central do homem na história, pois, mesmo sob condições determinadas, que não dependem de sua vontade, são os homens que fazem a história, ocupando dessa forma um papel essencial na construção, manutenção e transformação da sociabilidade. Felizmente, a realidade social é um permanente devir, sendo também uma permanente superação, visto que não há nada definitivo ou estático, ou seja, o que é pode mudar.

São também pressupostos do trabalho educativo o estímulo à autonomia dos usuários, à sua organização, mobilização e participação política. A autonomia caracteriza-se pela prática de sujeitos que, conscientes do seu lugar no mundo, tomam decisões e realizam escolhas, as quais vão sendo encaminhadas e encorajadas pelo profissional.

A organização, a mobilização e a participação política dos usuários são estratégias fundamentais para fortalecer suas lutas e instigar processos emancipatórios. Contudo, enquanto expressões das práticas educativas desenvolvidas em diferentes espaços sócioocupacionais são profundamente tensionadas no âmbito das relações burguesas, das contradições capital-trabalho.

A participação dos usuários nos espaços políticos - como conselhos, fóruns, assembleias, câmaras, conferências - e sua articulação junto aos movimentos sociais expressam formas coletivas de reivindicação de suas necessidades e de pressão para que o Estado assuma a sua responsabilidade na garantia legal, política e institucional dos direitos sociais. 
Considerando que a população pobre foi historicamente excluída dos processos políticos decisórios, há que se defender e fortalecer os espaços de exercício da democracia, como espaços de negociação e de disputa, tendo em vista assegurar os princípios de universalidade e de controle social. No entanto, Iamamoto (2002) adverte que a participação e as conquistas nesses espaços não estão definidas a priori; desse modo, tanto permitem aos sujeitos viver a dimensão do coletivo e a partilha de poder quanto podem fortalecer vícios tradicionais coronelistas, populistas e clientelistas no trato da coisa pública.

O assistente social atende uma população majoritariamente destituída de informações sobre seus direitos, cabendo-lhe dessa forma ser um agente de democratização dessas informações, produzindo um discurso contra ideológico que possibilite aos usuários, por meio dos conhecimentos adquiridos, reivindicar seus interesses. Assim, o saber é também uma expressão de poder, na medida em que instrumentaliza os sujeitos em suas lutas.

Desse modo, a mesma atividade da consciência subjetiva, produtora do saber, que é o lugar privilegiado da alienação, deixando-se levar facilmente pelo enviesamento ideológico, é também o instrumento qualificado para a libertação dessa alienação, pela crítica que pode fazer aos discursos do poder social e pela denúncia que pode apresentar contra esse enviesamento. (SEVERINO, 1995, p. 51).

Outro pressuposto fundamental do trabalho educativo refere-se ao posicionamento do profissional frente aos valores humano-genéricos, prefigurando a defesa da liberdade, dos direitos e da democracia. Tal posicionamento implica a adesão do assistente social a um projeto profissional vinculado à construção de uma nova ordem social, sem exploração de classe, etnia e gênero.

Consequentemente, o trabalho educativo na perspectiva crítica implica assumir posições teóricas e valores éticos imprescindíveis ao exercício profissional e incompatíveis com a insanidade do capitalismo, com suas relações perversas, individualistas e autoritárias. Essa é uma questão ética e política de suma “importância: o posicionamento de cada um e de todos a cada dia em face do possível mesmo que ele possa parecer ínfimo perto do que gostaríamos que fosse". (BARROCO, 2010, p.216).

E, por fim - e isso não significa dizer que não existem outros pressupostos para o trabalho educativo -, recusa-se a adoção de abordagens conservadoras e pragmáticas, as quais tratam a questão social e suas expressões como problemas individuais e morais. Quando as demandas dos usuários são avaliadas sob essa lógica, desconsidera-se que são consequências das contradições da sociedade burguesa, passando a serem entendidas como falência pessoal, uma questão de caráter ou um problema moral. 
Essa postura conduz também a um processo de criminalização dos usuários, por meio de ações e discursos que os penalizam, particularizando situações circunscritas à trama sóciohistórica. Por conseguinte, aparecem, nessa conjuntura, propostas educativas conservadoras, pontuais e fragmentadas, como, por exemplo, a disseminação de práticas terapêuticas, de mediação de conflitos e de intervenções centradas na responsabilidade individual.

A conjuntura atual encontra-se favorável às rogativas subjetivistas, bem como as estratégias profissionais de adaptação dos sujeitos e de apaziguamento das suas relações, expressando-se em abordagens paliativas, que ignoram os fundamentos da questão social e camuflam as desigualdades existentes.

A alienação que invade o modo de vida capitalista propicia essa apreensão, pois dissimula os fundamentos desses processos que se apresentam de modo aparente, como fenômenos verdadeiros e naturais. Além disso, a ideologia dominante corrobora com essa naturalização para preservar a dinâmica e os interesses burgueses. Daí a teoria critica não se deter com a aparência das coisas em si, com a forma como elas se traduzem imediatamente. "A razão não funda o real, mas persegue seu movimento reproduzindo-o, mentalmente, como lógica da coisa". (MARX, 2005, p. 39), como concreto pensado.

Em face disso, os assistentes sociais nem sempre reconhecem a incompatibilidade entre os direitos sociais e a lógica institucional, realizando intervenções centradas nos desígnios da instituição, mediante práticas "ditas educativas" que contribuem muito mais para manter a ideologia capitalista do que para questioná-la. Da mesma forma, mantém ações e narrativas que, embora antigas, apresentam-se com novas feições, como as iniciativas meritocráticas, que, sob o falso estigma de valorização dos sujeitos, são utilizadas como mecanismos de controle, exclusão e até mesmo de punição. Diante desse cenário, Simionatto (2001) adverte que

Pensar a educação no âmbito da crise do capitalismo contemporâneo é analisá-la sob
duas perspectivas: a subordinação das práticas educativas aos interesses do capital,
ou, o entendimento da educação enquanto apropriação de um conjunto de
conhecimentos, atitudes, habilidades e valores capaze de forjar a liberdade e o
reconhecimento do homem enquanto ser teleológico, criador e re(criador) da sua
própria história. (SIMIONATTO, 2001, p. 9).

Foi sob esta perspectiva que Gramsci problematizou a educação e os espaços em que é gerada e veiculada. Para ele, as classes subalternas (legado gramsciano) só poderão assumir um papel importante na sociedade capitalista no momento em que se libertarem das amarras ideológicas. Romper com a subordinação intelectual e superar o senso comum passam, segundo o autor, pela filosofia da práxis, e esta é uma das funções dos intelectuais: ampliar e 
auxiliar na construção de uma nova visão de mundo que seja expressão das necessidades e das aspirações dos trabalhadores.

Para Gramsci, as classes subalternas encontram-se presas ideologicamente à sociedade capitalista, estando privadas não apenas dos recursos materiais indispensáveis à sua sobrevivência, "mas também, muitas vezes, do conhecimento necessário para compreender a sociedade em que vivem e as circunstâncias em que se encontram". (YAZBEK, 2003, p.155); por essa razão, confere à cultura e à educação um papel fundamental no processo de desmistificação e de alteração da realidade.

Segundo o autor, a única forma de concretizar uma nova cultura é libertando os homens do senso comum e de sua filosofia espontânea, possibilitando-lhes, interpretar a herança histórica e cultural da humanidade e definir-se diante dela. Assim, destaca que as instituições políticas são instâncias capazes de fomentar a organização dos trabalhadores na construção de uma nova direção social. A construção dessa nova direção, por ele chamada de hegemonia, exige a presença de intelectuais, isto é, de homens e mulheres capazes de organizar e difundir a reforma intelectual, de firmar uma unidade orgânica com os trabalhadores, pautando-se por uma vontade coletiva nascida das suas demandas postas à sociedade no decorrer de seu desenvolvimento histórico.

Considerando que a construção da vontade coletiva é um processo longo e que demanda transformações econômicas e culturais, o assistente social deve, nessa perspectiva, exercer o papel político de proceder à crítica das ideologias dominantes e, a partir disso, incitar a formação de um pensamento que expresse a concepção proletária de mundo, trabalhando em prol da formação "de elites de intelectuais de novo tipo, que surjam diretamente da massa e que permaneçam em contato com ela para tornarem-se seu sustentáculo". (GRAMSCI, 1999, p. 110).

A busca ética do profissional comprometido com os trabalhadores deve ser a de que, mediante a denúncia e a explicitação de situações desumanizantes,encontrem-se alternativas para seu enfrentamento.

\footnotetext{
A existência, porque humana, não pode ser muda, silenciosa, nem tampouco pode nutrir-se de falsas palavras, mas de palavras verdadeiras, com que os homens transformam o mundo. Existir, humanamente, é pronunciar o mundo, é modificá-lo. $\mathrm{O}$ mundo pronunciado, por sua vez, se volta problematizado aos sujeitos pronunciantes, a exigir deles novo pronunciar. Não é no silêncio que os homens se fazem, mas na palavra, no trabalho, na ação-reflexão. (FREIRE, 1977, p. 90).
}

Não há como conhecer a realidade social sem entender os mecanismos que geram à opressão e à dominação da classe trabalhadora na sociedade capitalista. Sem dúvida, a 
educação popular revela-se um instrumento importante no processo de formação da liberdade, da cidadania e do sujeito político, por consequência de transformação social. Por isso mesmo, não se limita, como recorda Freire (2013), à apropriação da escrita e da leitura; mais do que isso, pressupõe ler criticamente o mundo, para alterá-lo.

Sob este aspecto, não é suficiente conhecer a realidade, dado que os homens e mulheres se tornam sujeitos políticos na práxis, ou seja, quando adquirem consciência frente ao mundo e agem sobre ele. Assim, a noção de prática, na perspectiva marxista, define-se em oposição ao caráter especulativo e contemplativo da filosofia idealista, pois é entendida não como mera atividade da consciência, mas como atividade real e reflexiva do homem social. Segundo Marx e Engels (2001, p. 100), é na práxis que o homem deve "provar a verdade, isto é, a realidade e a força, a terrenalidade do seu pensamento. A discussão sobre a realidade ou a irrealidade do pensamento - isolado da práxis-é puramente escolástica".

Nesses termos, o trabalho educativo no campo profissional do Serviço Social exige intervenções profissionais junto aos usuários que desmistifiquem a realidade e os antagonismos que estruturam a sociedade burguesa para fortalecer seus interesses e as disputas no campo material e ideológico.

\section{Considerações finais}

Sintetizando as reflexões apresentadas neste artigo, reafirma-se que, na direção do projeto ético-político, o trabalho educativo, no campo profissional do Serviço Social, tem como eixo central a formação da consciência critica dos sujeitos para sua ação concreta e reflexiva sobre o mundo. Nestes termos, busca-se, por meio das práticas educativas, levar os usuários a se perceberem como sujeitos políticos, capazes de questionamentos sobre a ordem social e de reivindicações sobre seus diretos, com vistas ao atendimento de suas necessidades.

Ao considerar, como Gramsci (2004), que a luta social se trava também no campo ideológico, compreende-se que, nesse terreno, o Serviço Social tem uma importante função a cumprir, sendo chamado a mobilizar consciências, denunciar processos opressores e impulsionar lutas coletivas.

Se a busca é pela construção de uma nova hegemonia, o trabalho educativo deve avançar os limites das intervenções individuais, pois, embora os sujeitos sofram muitas vezes as situações de maneira subjetiva e particular, essas situações são socialmente construídas, ou seja, são resultados do modo de vida na sociedade capitalista. Nesse sentido, é fundamental construir espaços de reflexão crítica sobre as condições de vida dos usuários, incentivando sua ação no campo sociopolítico. Tais experiências possibilitam aos sujeitos experimentar suas 
práticas como formas de resistência, permitindo alargar o espaço de sociabilidade e de intervenção, no qual passam a se reconhecer mutuamente, a decidir e a agir em conjunto.

A esse respeito, Martinelli (1993, p.141) ressalta que, na perspectiva do materialismo histórico-dialético, devem-se privilegiar ações coletivas valendo-se "de mediações que concorram para a superação das problemáticas vivenciadas e para a construção de novas totalizações".

Compreende-se, então, que o trabalho educativo no Serviço Social, pretende nas palavras de Gramsci, contribuir para a construção e o fortalecimento de uma contrahegemonia, objetivo que se coloca como essencial em tempos de colapso da sociedade brasileira. Diante da crise estrutural do capital, da depredação de todos os direitos sociais e da violência cotidiana que atravessa, sobretudo, a vida dos trabalhadores mais empobrecidos, é urgente pensar a educação como prática de resistência e de conscientização popular.

O conservadorismo e o autoritarismo explícitos no país evidenciam a permanência de traços de sua estrutura arcaica, violenta e escravista. Um país cuja formação ocorreu sob a exploração e o ódio aos pobres, índios e negros e que, historicamente, vem perpetuando tais práticas contra esses e outros grupos que hoje têm se tornando alvo da necropolítica (Mbembe, 2016), a exemplo da comunidade LGBTQ+. Nesse sentido, o momento atual solicita-nos nas palavras de Iamamoto (2002, p.33), "reassumir o trabalho de base, de educação, mobilização e organização popular, que parece ter sido submerso do debate teóricoprofissional".

O trabalho educativo, assim como outras mediações e estratégias profissionais, deve considerar a necessidade imediata postulada pela conjuntura atual brasileira de práticas voltadas para ampliar consciências, para a defesa cultural dos povos dominados e para a interiorização dos valores humano-genéricos defendidos pelo Serviço Social, colaborando, dessa forma, para que os sujeitos se descubram livres e conscientes para lutar e resistir. Como recorda Freire é preciso fazer da opressão um motor de reflexão, de contestação e de luta cotidiana dos oprimidos.

\section{COLLAPSE TIMES, FIGHT TIMES: CONTRIBUTIONS OF EDUCATIONAL WORK IN SOCIAL WORK}

\section{Abstract}

This article reflects on the possibilities of educational work in the professional field of Social Work and its ideo-political implications in the daily life of the subjects attended by social workers intheir different performance spaces. The Brazilian conjuncture, marked by enormous challenges arising from the neoliberal offensive in full swing, the advance of the 
extreme right and the irrationalism that has taken over the country, especially in the last two years (pre and post Bolsonaro election), has demanded from professionals interventions that recover and / or emphasize educational work with the user population, taking advantage of political-pedagogical mediations that contribute to the formation of critical awareness, aiming at the construction of counter-hegemonic ideas and practices as well as the recognition of the spoliation processes that they experience so that they seek to meet their needs. In this sense, the contribution of Gramsci and Paulo Freire's thoughts is pointed out to enable the educational work in the Social Work under the professional ethical-political project, so that it is possible to broaden perceptions, meanings and actions, as well as to dare and resist the collapse installed in Brazilian society.

Keywords: Social Service, Educational Work, Contributions from Grasmci and Paulo Freire.

\section{REFERÊNCIAS}

BARROCO, Maria Lucia Silva. Ética: fundamentos sócio-históricos. 3. ed.São Paulo: Cortez, 2010.

BEHRING, Elaine Rossetti. Brasil em Contra-Reforma: desestruturação do Estado e perda de direitos. São Paulo, Cortez, 2003.

COSTA, Antonio Carlos Gomes da.As bases éticas da ação sócio-educativa: referenciais normativos e princípios norteadores. Brasília: Secretaria Especial dos Direitos Humanos da Presidência da República - SEDH/PR, 2004.

FAERMANN. Lindamar Alves. O uso dos instrumentos e das técnicas no serviço social na perspectiva crítico-dialética: mediações necessárias. 2014. 186 f. Tese(Programa de PósGraduação em Serviço Social - Mestrado e Doutorado) - Pontifícia Universidade Católica de São Paulo, São Paulo, 2014.

FREIRE, Paulo. Pedagogia do oprimido. Rio de Janeiro: Paz e Terra, 1977.

Desmistificação daconscientização. In: TORRES, C. A. Consciência e história: a práxis educativade Paulo Freire. (Antologia detextos selecionados de Paulo Freire). São Paulo: Loyola, 1979.

.Educação e mudança. Rio de Janeiro: Paz e Terra, 2013.

2005 .

.Professora sim, tia não:cartas a quem ousa ensinar. 15. ed. São Paulo: Olho d’Água,

GIL, Antônio Carlos. Métodos e técnicas de pesquisa social. São Paulo: Atlas, 1999.

GRAMSCI, Antonio. Cadernos do cárcere. 3. ed. Rio de Janeiro: Civilização Brasileira, 2004. Vol. 2.

.Introdução ao estudo da Filosofia. A Filosofia de Benedetto Croce. Rio de Janeiro: Civilização Brasileira, 1999.

GUERRA, Yolanda AparecidaDemétrio. A instrumentalidade no trabalho do assistente social. Curitiba: Cedeps, 2010. 
GHIRALDELLI, Junior Paulo. O que é pedagogia. São Paulo: Brasiliense, 2004. (Coleção Primeiros Passos).

IAMAMOTO, Marilda Villela. Renovação e conservadorismo no Serviço Social. 4. ed. São Paulo: Cortez, 1993.

.O Serviço Social na contemporaneidade: trabalho e formação profissional. 3. ed. São Paulo: Cortez, 2002.

Projeto profissional, espaços ocupacionais e trabalho do assistente social na atualidade. In: Conselho Federal de Serviço Social - CFESS. Atribuições privativas do(a) assistente social em questão. Brasília, 2002.

IASI, Mauro Luis. Ensaios sobre consciência e emancipação. 2. ed.São Paulo: Expressão Popular, 2011.

MARTINELLI, Maria Lúcia. Notas sobre mediações: alguns elementos para sistematização da reflexão sobre o tema. Revista Serviço Social \& Sociedade, n. 43, 1993.

MARX, Karl; ENGELS, Friedrich. Manifesto do Partido Comunista. São Paulo: Cortez, 1998.

.A ideologia Alemã.São Paulo: Martins Fontes, 2001.

MARX, Karl. Crítica da filosofia do direito de Hegel. São Paulo: Boitempo, 2005.

.Sobre a questão judaica. São Paulo: Boitempo. 2010.

MBEMBE, Achilles. Necropolítica:biopoder, soberania, estado de exceção, política da morte. Revista Arte \& Ensaios.n. 32, p. 123-151.Rio de Janeiro: UFRJ, 2016.

MIOTO, Regina Célia Tamaso. Orientação e acompanhamento a indivíduos, grupos e famílias. In: Serviço Social: Direitos sociais e competências profissionais. Brasília: CFESS/ABEPSS, 2009. p. 497-512.

MIOTO, Regina Célia Tamaso; LIMA, Telma Cristiane Sasso de. A dimensão técnicooperativa do Serviço Social em foco:sistematização de um processo investigativo.

RevistaTextos \& Contextos, Porto Alegre, v. 8 n. 1, p. 22-48,jan./jun., 2009.

NETTO, José Paulo. Ditadura e Serviço Social: uma análise do serviço social no Brasil pós64. 5. ed. São Paulo: Cortez, 2001.

PRATES, Jane Cruz. A questão dos instrumentais técnico-operativos numa perspectiva dialética crítica de inspiração marxiana. Revista Textos \& Contextos, Porto Alegre, n. 2, dez., 2003.

Formar para além do mercado e para o uso substantivo do instrumental de trabalho.

Revista Textos \& Contextos, Porto Alegre, v. 12, n. 1, p. 01 - 06, jan./jun. 2013.

RAICHELIS, Raquel. Legitimidade e Poder público. 2. ed. São Paulo: Cortez, 1988. 
RIOS, Terezinha Azerêdo. As pessoas que a gente não vê. In: BAPTISTA, MyrianVeras (Coord.). Abrigo:comunidade de acolhida e socioeducação. São Paulo: Instituto Camargo Corrêa, 2006.

SAVIANI, Dermeval. O trabalho como princípio educativo frente as novas tecnologias. In: FERRETTI, Celso João et al. (Orgs.). Novas tecnologias, trabalho e educação: um debate multidisciplinar. Petrópolis: Vozes, 1986.

SEVERINO, Antonio Joaquim. O poder da verdade e a verdade do saber. In: MARTINELLI, Maria Lúcia; RODRIGUES, Maria Lucia; MUCHAIL, SalmaTannus (Orgs.). O uno e o múltiplo nas relações entre as áreas do saber. São Paulo: Cortez, 1995. p. 46-54.

SILVEIRA, Jucimeri Isolda. Sistema Único de Assistência Social: institucionalidade e processos interventivos. Revista Serviço Social e Sociedade, São Paulo, n. 98, p. 335-361, 2009.

SIMIONATTO, Ivete. Gramsci:sua teoria, incidência no Brasil, influência no Serviço Social. 3. ed. São Paulo: Cortez, 2001.

VASCONCELOS, Ana Maria. A prática do serviço social: cotidiano, formação e alternativas na área da saúde. 8 ed. São Paulo: Cortez, 2012.

YAZBEK, Maria Carmelita. O Serviço Social como especialização do trabalho coletivo. In: Cead/UnB (Org.). Capacitação em Serviço Social e Política Social. Módulo 2. Brasília: Cead/UnB, 1999.

. Classes subalternas e assistência social. 4. ed. São Paulo: Cortez, 2003.

O Serviço Social e o movimento histórico da Sociedade brasileira. In: Conselho Regional de Serviço Social/São Paulo - CRESS (Org.). Legislação brasileira para o Serviço Social: coletânea de leis, decretos e regulamentos para instrumentalização do (a) assistente social. 2. ed. São Paulo:CRESS, 2006. p. 12-29

Data de recebimento: 10/01/2020

Data de aceite: 18/03/2020

\section{Sobre as autoras:}

Lindamar Alves Faermann é Assistente Social, Mestre em Serviço Social pela PUC-SP (2007), Doutora em Serviço Social pela PUC-SP (2014). Professora da Universidade de Taubaté -UNITAU desde 2006. Atua como docente no Curso de Graduação e da PósGraduação. Atualmente coordena o Curso de Serviço Social da UNITAU e curso de Pósgraduação Lato Sensu em Instrumentalidade Profissional do Assistente na mesma Instituição. Membro do corpo editorial da Revista Emancipação da Universidade Estadual de Ponta Grossa. Líder do Grupo de Estudos "Serviço Social, Trabalho e Políticas Sociais", certificado pelo $\mathrm{CNPq}$, com produções na área de fundamentos do Serviço Social, trabalho e política educacional. Membro do Núcleo Docente Estruturante do Curso de Graduação em Serviço Social da UNITAU. Possui experiência profissional na área de educação e assistência social. Endereço Eletrônico: lindafaermann@yahoo.com.br 
Angela Michele Suave possui graduação em Serviço Social pela Universidade do Vale do Paraíba (2002), mestrado em Programa de Estudos Pós-Graduados em Serviço Social pela Pontifícia Universidade Católica de São Paulo (2009) e doutorado em Programa de Estudos Pós-Graduados em Serviço Social pela Pontifícia Universidade Católica de São Paulo (2016). Atualmente é professor assistente da Universidade de Taubaté no Departamento de Serviço Social, no Programa de Mestrado em Desenvolvimento Humano e nos cursos de especialização de Instrumentalidade Profissional em Serviço Social e de Intervenção com Famílias na área da Psicologia. Coordenadora dos Projetos de Extensão "Desenvolvendo a Educação Socioemocional na Escola" com crianças do Ensino Infantil da rede municipal do município de Taubaté e "Apoio e Prevenção ao Suicídio de Jovens". Presta assessoria científica à Revista Políticas Sociais da Universidade Federal do Maranhão. Editora executiva da Revista Ciências Humanas. Tem experiência na área de Serviço Social, atuando principalmente nos seguintes temas: serviço social, movimentos sociais, política social, direitos sociais e famílias. Trabalhou como assistente social em projeto interdisciplinar, envolvendo as áreas da Assistência Social, Educação e de Saúde para o atendimento de famílias com crianças e adolescentes vítimas de violência doméstica. Coordenou e participou de outros projetos de extensão nas áreas da Educação, Direito Social e Assistência Social. Endereço Eletrônico: michelesuave@ hotmail.com 